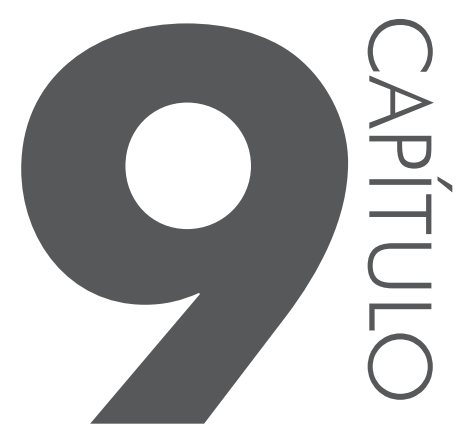

\title{
Formação do professor para a Educação Inclusiva
}

Jackeline Lima Farbiarz, Doutora, Pontifícia Universidade Católica do Rio de Janeiro (PUC-Rio)

\section{INTRODUC̣ÃO}

O presente artigo visa sintetizar as discussões desenvolvidas no grupo de trabalho (GT) "Formação do professor, práticas de ensino-aprendizagem, produção e uso de materiais, recursos e tecnologias assistivas com foco na educação inclusiva” que se reuniu no evento SILID/SIMAR ${ }^{1}$, cujo objetivo era o de

1 Tanto neste quanto nos outros artigos que compõem o presente livro, quando mencionarmos um determinado Grupo de Trabalho (GT), os resumos das comunicações dos autores poderão ser acessados em http: <//www.designnaleitura.net.br/silid-simar/caderno_resumos/Caderno\%20de\%20 Resumos \%20V\%20SILID\% $>$. Neste caso específico, os seguintes artigos podem ser acessados em: "Discutindo estratégias para o ensino de literatura no contexto de educação de jovens e adultos surdos" - disponível em: <http:/www.proceedings.blucher.com.br/article-details/discutindo-estratgias-para-o-ensino-de-literatura-no-contexto-de-educao-de-jovens-e-adultos-surdos-22594>. "Práticas singulares de formação" - disponível em: <http://www.proceedings.blucher.com.br/ article-details/prticas-singulares-de-formao-22595>.

"Roteiro Para Avaliação E Seleção De Atividades Didáticas De Língua Inglesa Na Compreensão Escrita" - disponível em: <http://www.proceedings.blucher.com.br/article-details/roteiro-para-avaliao-e-seleo-de-atividades-didticas-de-lngua-inglesa-na-compreenso-escrita-22596>. 
fomentar discussões interdisciplinares que ancorassem a formação/qualificação do professor nesse contexto.

Entende-se aqui que a educação inclusiva demanda, por parte da sociedade civil e do Estado, o compromisso com a formação e qualificação do educador. Essas devem voltar-se para práticas que abarquem metodologias, materiais, recursos e tecnologias assistivas que promovam a redução das desigualdades educacionais com respeito às diferenças.

Embora o discurso vigente nas políticas públicas para à Educação Inclusiva valorize a diversidade e a promoção do bem-estar do aluno, conforme já abordado no Capítulo $8^{2}$, sob a perspectiva da constituição da identidade, o cotidiano das salas de aula traz para o professor desafios reais que geram inúmeras incertezas concretizadas em questionamentos e posicionamentos controvertidos. Alunos com déficit de atenção, hiperatividade, autismo, síndrome de down; alunos cegos, surdos, com comprometimento motor e ainda alunos privados do saber básico, como os vinculados à educação de jovens adultos, entre outros transtornos, deficiências e injustiças estão nas salas de aula, mas não necessariamente participam delas. Práticas, metodologias, materiais, livros, recursos e tecnologias, muitas vezes, mantêm a segregação em detrimento à inclusão, percebida como promotora do direito efetivo à escolarização.

Inicialmente, este artigo adota como percurso metodológico um convite ao leitor para participar de sua tessitura em busca de situações de inclusão na rememoração de seu cotidiano escolar/acadêmico. Ele apresenta, também, uma pesquisa bibliográfica com vistas a traçar um panorama da política de inclusão no cenário nacional. Nele estão sintetizadas, ainda, as discussões desenvolvidas no GT. E, finalmente, há aqui a proposição do design social participativo-inclusivo como eixo condutor da interdisciplinaridade necessária para abordar a inclusão.

\section{PREÂMBULO}

Observe a imagem abaixo:

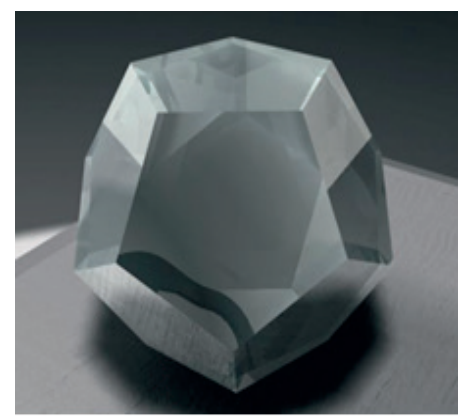

Figura 9.1: Simulação 3D da figura geométrica dodecaedro. Fonte: LINC-Design

2 Silva e Bastos tratam de questões para a constituição de identidades com foco nas diferenças no Capítulo 8 deste livro. 
Trata-se de uma representação tridimensional de um dodecaedro. O que ele traz de especial?

Platão (427 a.C - 347 a.C), no livro Timaeus, afirma que o dodecaedro, como elemento geométrico, é o símbolo da Harmonia Cósmica. Nas palavras do filósofo, a ordem do universo constituiu-se por intermédio de formas e números essenciais que atuavam como conexão entre o reino superior e o inferior a partir do caos primordial. Por essa perspectiva, os elementos essenciais seriam aqueles cujas arestas e ângulos internos fossem iguais, cabendo a estes a composição dos elementos básicos da natureza: cubo $=$ terra; tetraedro $=$ fogo; octaedro $=$ ar; icosaedro = água; e dodecaedro = éter (considerado a quinta essência, o elemento mais importante).

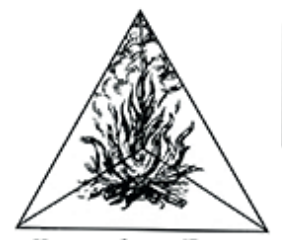

Tetraedro - Fogo

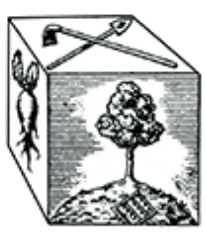

Cubo - Terra

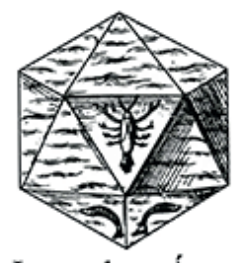

Icosaedro - Água

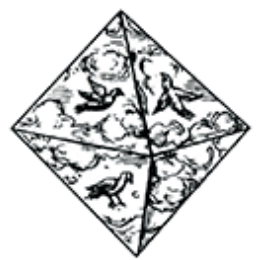

Octaedro - Ar Dodecaedro-Universo

Figura 9.2: Sólidos de Platão. Fonte: http://cmup.fc.up.pt/cmup/pick/Manhas/PoliedrosPlata02.jpg

Segundo Platão, o dodecaedro, pelo valor que alcançam as aberturas de seus ângulos, é o sólido que mais se aproxima da perfeição da superfície esférica. Suas doze faces pentagonais seriam representativas da proporção áurea que se repete em toda natureza. Somando-se as questões de simetria e proporcionalidade, o próprio número doze, quantidade de pentágonos regulares que compõem o dodecaedro, tem representação singular e mítica ao longo da história da humanidade: doze meses no ano, doze signos no horóscopo ocidental, doze signos no horóscopo chinês, doze tribos de Israel, doze conselhos do Dalai Lama, doze apóstolos de Cristo, doze cavaleiros da Távola Redonda e etc.

Antes de Platão, Pitágoras (570 a.C - 490 a.C), em sua cosmogonia, já havia sustentado que o dodecaedro seria a quintessência criadora dos quatro elementos responsáveis pelo universo em sua forma: água, terra, ar e fogo. De acordo com o também filósofo e matemático, esse sólido carregaria consigo o valor de ser o único poliedro regular capaz de inscrever todos os demais poliedros.

No século XVI, o astrônomo Kepler, estudando o sistema solar, usou os cinco sólidos num modelo para explicar os movimentos dos planetas - sólidos que, para ele, correspondiam à perfeição geométrica absoluta. 
É no século XX, contudo, que, considerando que os cinco sólidos estavam inscritos na circunsfera, o inventor, designer e arquiteto Buckminster Fuller (1979) demonstra que, apesar das pessoas aprenderem que a terra não é plana e apesar de terem desenvolvido conhecimentos em distintas disciplinas, elas continuam a pensar e a produzir em e para um mundo planificado.

Utilizando-se de uma situação para explicar seu posicionamento, ele pede para um menino desenhar um triângulo no chão e, ao fazê-lo, pede ao mesmo menino que explique o que vê. Fuller constata a limitação na estrutura do pensamento do meninopor este não identificar que ao desenhar um triângulo, na verdade está desenhando quatro e atuando na circunsfera (não apenas na planificação, como pensa).

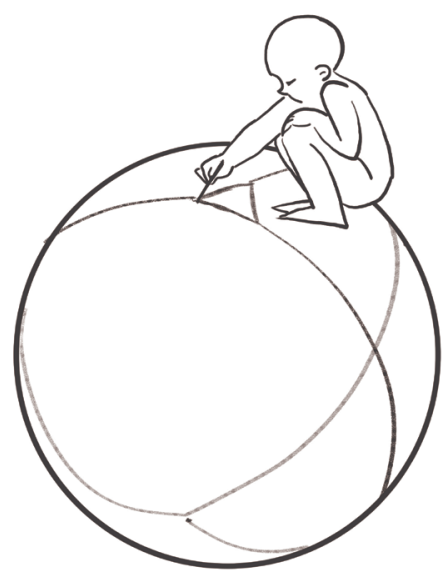

Figura 9.3: Estrutura planificada. Fonte: LINC-Design

A partir do exemplo, ele enfatiza que:

Se realmente fosse um plano, avançando infinitamente para todos os lados, então haveria infinito espaço para se poluir e infinitos recursos para substituir aqueles já exauridos. De fato, é esta a forma como parecia ser no passado, e nós ainda estamos nesta estrutura mental. Da mesma forma, ainda vemos o sol descendo à noite $\mathrm{e}$ subindo de manhã, apesar de sabermos, há 500 anos, que ele não está fazendo isso. Nossos sentidos podem estar muito desencaixados com o que 'sabemos' teoricamente. (1979, p. 9-10. Tradução Julia Teles).

Dessa perspectiva, ele defende uma grande mudança no pensamento, de forma a termos a sinergia em mente e pensarmos nas relações entre todas as coisas. Fundamentalmente, em sua concepção, para que a humanidade sobreviva no planeta é 
preciso quebrar a estrutura planificada de pensamento, refletindo sobre o todo sempre, para que seja possível a criação de um sistema que inclua toda a humanidade, sob a pena de seu padecimento.

\section{Pressuposição e objetivo}

\section{Inscrição de todos num todo: harmonia}

A recuperação de informações acerca da investigação da dimensão essencial e ontológica do mundo real mostra que data de antes de Cristo a busca pela razão de ser do homem no planeta Terra e pela forma perfeita para a sua inscrição. Uma rápida procura no dicionário de sinônimos do editor de textos Microsoft Word pela definição da palavra harmonia leva aos seguintes resultados: acordo, beleza, coerência, coesão, composição, concordância, elegância, equilíbrio, proporção, reciprocidade. Estes termos podem gerar uma leitura em que a harmonia cósmica representada no dodecaedro inscrito na circunsfera - sua capacidade de inscrição de todos num todo - , carregaria consigo a potência da inclusão.

Em linhas gerais, o encontro com os estudos citados, com a compreensão da forma representativa dessa harmonia, poderia desencadear o sentimento de pertencimento pelo somatório de proporção, coesão e reciprocidade. Isso mesmo cientes, e cabe aqui o reparo, de que Platão compactuava com o procedimento vigente em Esparta e Atenas de eliminar ou abandonar pessoas com deficiências como forma de equilíbrio demográfico, principalmente quando a pessoa em questão fosse dependente economicamente. $\mathrm{O}$ pensamento se justifica, pois naquela época predominava a visão de serem os deficientes sub-humanos e, como tais, considerados dissociados da dimensão essencial do mundo real; assim, eles não ocupavam o lugar da exclusão ou da negação, mas sim o não lugar da inexistência.

Fato é que séculos e mais séculos se passaram desde que foram realizados os estudos que reconhecem um poliedro harmônico e, consequentemente, inclusivo. Porém, também é fato que a potência criativa e inovadora do ser humano da atualidade parece, em muitos sentidos, constituir-se, ainda hoje, em dissonância com os preceitos de harmonia e inclusão. Muitas das ações experimentadas encontram-se restritas a formas tidas como não universais e imperfeitas, como exclusivas, pressuposição esta que motivou a constituição do GT aqui apresentado, por demandar troca de experiências, investigação e ação. É a partir desse viés que o presente artigo visa reunir olhares e ações sobre a educação inclusiva apresentados nos simpósios, para fomentar discussões interdisciplinares que ancorem a formação/qualificação do professor nesse contexto. 


\section{Delimitação}

\section{Inscrição de todos em todos excludentes: desarmonia.}

Observe, agora, o seu local de leitura do presente artigo. Procure representá-lo graficamente:
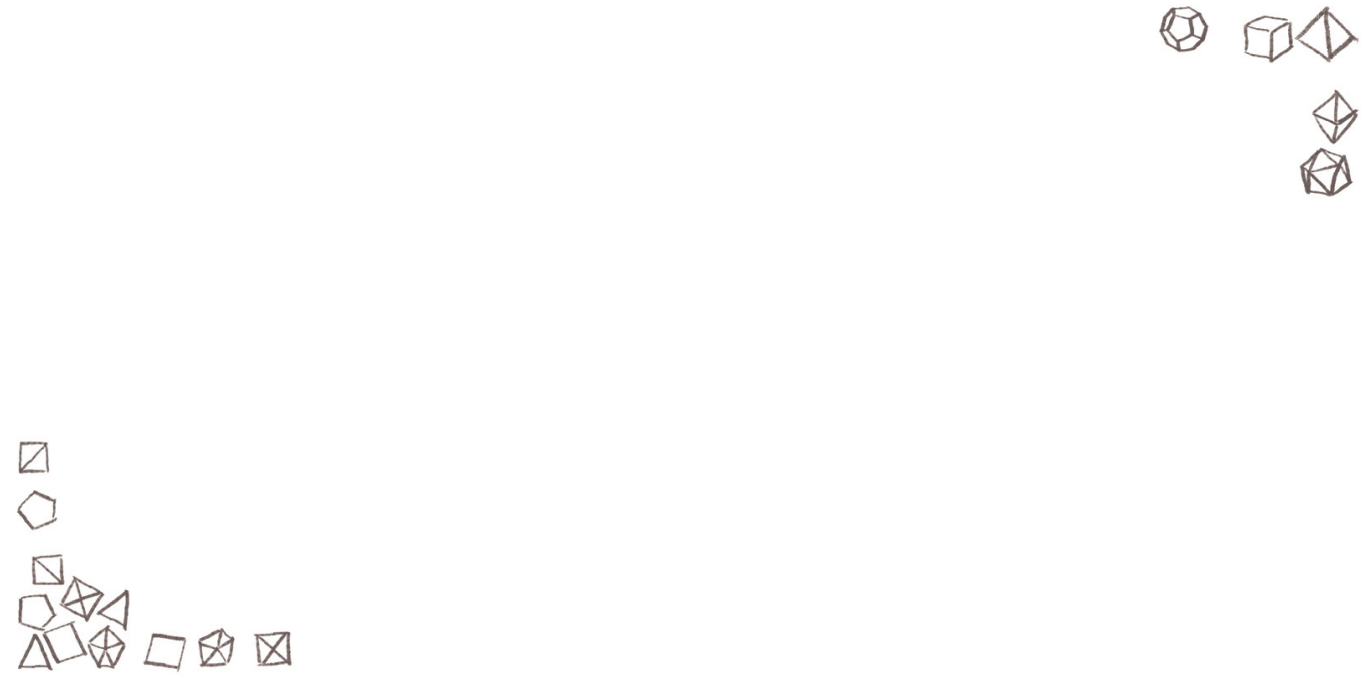

Figura 9.4: Espaço para representação. Fonte LINC-Design

A não ser que você esteja desvirtuando protocolos de leitura institucionalizados, decorrentes da produção de sentidos da leitura (GOULEMOT; In: CHARTIER, 1999), é bastante provável que esteja sentado em uma cadeira, segurando o livro ou apoiando-o em uma mesa para possíveis anotações no texto; ou, ainda, é possível que esteja lendo este artigo por meio de uma tela de computador, um "tablet" ou "ebook reader". Veja se você não está circunscrito em formas próximas ao sólido cubo, envolto por ângulos retos, dentre os apresentados por Platão ao discutir os elementos essenciais.

Pense agora nos ambientes formais que participaram da constituição de sua formação: pense no lugar onde você mora; na escola que frequentou ou frequenta, nos consultórios dos seus médicos; pense em cidades; concentre-se naquelas que mantêm viva a experiência com a natureza; mesmo assim, ângulos e mais ângulos retos, "caixas e mais caixas", limites, domínios, disciplinas e fragmentações provavelmente participaram da composição de sua imaginação.

Veja, por exemplo, se a Figura 9.5, caso você seja morador de uma grande cidade, não lhe traz a possibilidade de reconhecimento: 


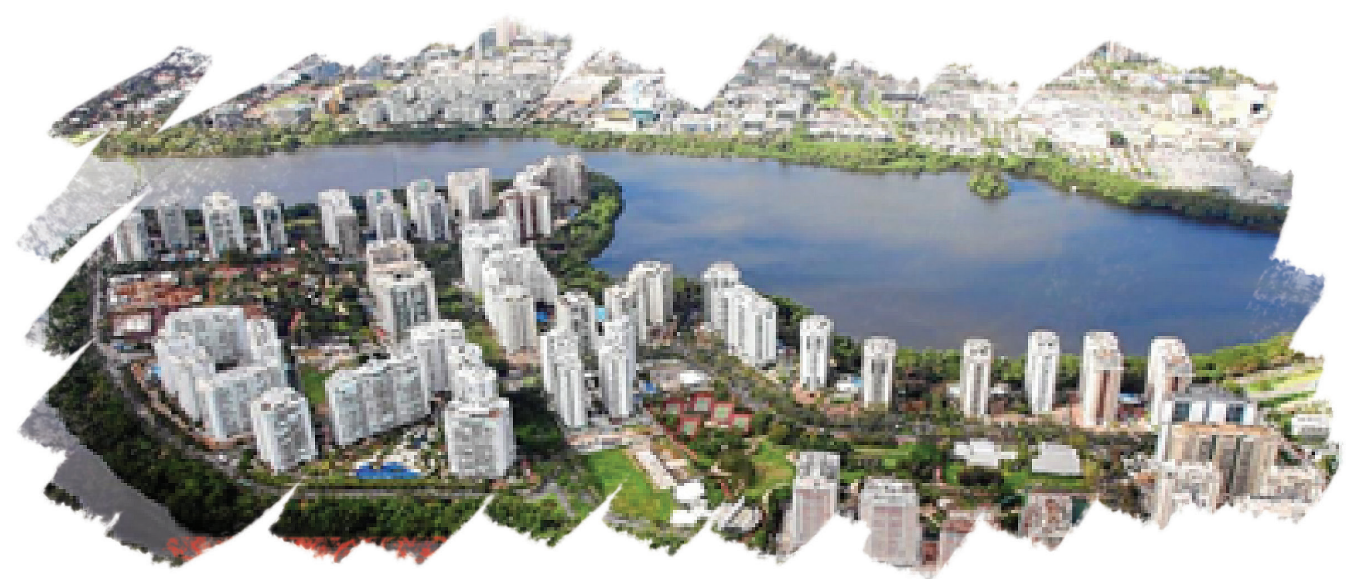

Figura 9.5: Barra da Tijuca, cidade do Rio de Janeiro. Fonte: http://og.infg.com.br/rio/13857646-3cd-laa/FT150 OA/550/2014-748982733-2014090535456.jpg_20140905.jpg

Certo é que, mesmo após a passagem de tantos séculos, as cidades foram se constituindo por meio de poliedros que mantêm os indivíduos "encaixotados", organizados em "cubículos”. A constatação é a de estar limitado por formas que, dentre os elementos essenciais, a partir dos quais Platão desenvolve a sua reflexão, mais se aproximam da forma cúbica, associada pelo filósofo ao elemento terra, em sua busca pela composição dos elementos essenciais da natureza e em seu subsequente encontro com o dodecaedro (modelo do universo).

Pense, então, nesse elemento terra como essencial da natureza. Em uma composição de várias das definições a ele agregadas, o elemento pode ser entendido como a massa que se distancia dos oceanos e da atmosfera por sua solidez e que abriga o mundo da natureza física. Na composição de seu conceito, agregam-se valores como "ter os pés na terra" e como sustentar-se na realidade material em oposição às ações espirituais, etéreas, abstratas e imaginativas. Ele, engloba, ainda a neutralidade que caracteriza o fio neutro de uma instalação elétrica, sendo a cautela e o equilíbrio a sua força motriz em prol da eficiência no suprimento de necessidades básicas. A predominância dessa força e a solidez do elemento, trazem como característica o ceticismo e a resistência a mudanças, além da valorização da análise e da perseverança.

Encaixotados, envoltos por ângulos retos, limitados, concisos, cientes de si mesmos, distantes do universo anunciado no dodecaedro. Os termos mencionados poderiam facilmente ter participado (e alguns participaram participaram) do histórico Seminário sobre Interdisciplinaridade nas Universidades, realizado 
em 1970 em Nice, na França. No evento, houve um avanço, embora ainda relativo, no sentido de trazer precisão para os termos e conceitos utilizados com a finalidade de expressar os diferentes tipos e formas da pesquisa e da prática interdisciplinar. Lá discutiram-se as principais tendências vigentes na percepção de pesquisadores de áreas e países diversos, como Boisot (França), Heckhausen (Alemanha), Jantsch (Áustria) e Piaget (Suíça).

Independente da perspectiva ou da ênfase, certo é que os debatedores, em especial Heckhausen, adotaram como um dos caminhos para se discutir o tema do Seminário a delimitação do conceito de disciplinaridade sintetizado a seguir, por Japiassu (1977, p. 60) e Fazenda (1979, p. 29):

- domínio material, constituído pelo conjunto de objetos de que se ocupa uma disciplina;

- domínio de estudo, definido pelo ângulo específico a partir do qual a disciplina delimita seu domínio material;

- níveis de integração teórica dos conceitos fundamentais e unificadores de uma disciplina;

- métodos próprios para apreender e transformar os fenômenos;

- instrumentos de análise que levam em conta a estratégia lógica, os raciocínios matemáticos e a construção de modelos;

- aplicações; e

- contingências históricas.

A opção dos pesquisadores contribuiu para a associação da disciplinaridade com palavras como especificidade, unificação, domínio, aplicação e modelo - palavras estas que dialogam favoravelmente com termos como limites, localização e exclusão - palavras que se distanciam da inscrição de todos num todo, da harmonia validada na forma dodecaedro, tal qual conceituada por Pitágoras e Platão; palavras que perduraram no contexto educacional por vários séculos.

Especificamente no Brasil, foram vivenciados momentos históricos perversos onde aquilo que fugia ao modelo, que distorcia um domínio material, quando muito, ocupava lugares marginalizados de exclusão social. A implantação da roda dos expostos, onde crianças com deficiência eram abandonadas para serem cuidadas por freiras nos séculos XVIII e XIX serve de exemplo. Surge no século XVIII, conforme apresentado a seguir no gráfico de proporção de crianças entregues em rodas brasileiras entre 1745 e 1829, o processo de institucionalização/ disciplinaridade dessas crianças: 


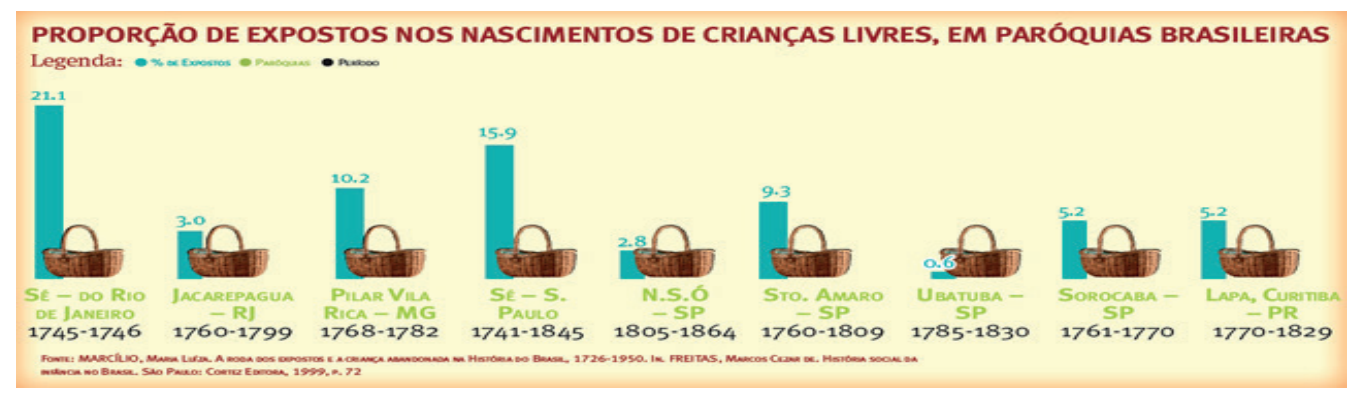

Figura 9.6: Dados Roda dos Expostos 1745-1829. Fonte: MARCíLIO, M. In: FREITAS, M., 1999, p. 72

Perdurou como norma, um cenário de valorização da fragmentação, da limitação em detrimento da harmonia, da coesão e do equilíbrio. No Brasil, por exemplo, a Constituição de 1824 privava do direito político o incapacitado físico ou moral. No contexto da disciplinaridade e da institucionalização, em 1874, o Hospital Juliano Moreira é criado como espaço específico para atendimento a pessoas com deficiência mental. Em 1903, é aberto no Rio de Janeiro o Pavilhão Bourneville, primeira escola especial para crianças anormais. Priorizava-se, então, uma visão higienista atrelada à medicina.

Inscrição de todos em todos excludentes + inscrição de todos em partes de um mesmo todo

É somente a partir da década de 1930, com a divulgação do Manifesto dos Pioneiros da Educação Nova (1932) no Brasil, que ao contexto da exclusão e da fragmentação opõem-se conceitos como respeito à individualidade e atenção à diversidade para, a partir de sua função democratizadora, busca-se propiciar a igualdade de oportunidades. Há, então, uma mudança de paradigma, na qual a visão médico-higienista cede lugar à visão psicológica sobre a sociedade. Apesar deste significativo avanço, no qual a inscrição de todos em todos excludentes cedeu lugar à inscrição de todos em partes de um mesmo todo, também (e ainda) no novo cenário não se chegou positivamente à inscrição de todos num todo, entendida como harmonia. Em alguns casos, oportunidades iguais são ofertadas em um mesmo todo configurado a partir de domínios, limites específicos. Surgem, no novo modelo, as chamadas classes especiais, formadas idealmente a partir da aplicação de testes cognitivos desenvolvidos principalmente com a chegada ao Brasil da educadora e psicóloga Helena Antipoff.

O novo paradigma, entretanto, não elimina a ideologia anteriormente predominante, de inscrição de todos em todos excludentes. Coexistem, assim, 
instituições com classes especiais e instituições com foco exclusivo na educação especial. Escolas públicas, privadas, beneficentes, filantrópicas - vários domínios, vários rótulos, diferentes "caixas" assumem, cada uma a seu modo, um lugar na Educação Especial, em comum a segregação em um mesmo todo revestido do conceito de integração, ou em todos excludentes com valores disciplinares solidificados.

\section{Significação}

\section{Inscrição de todos no todo}

Somente na década de 1970 é constituído o Cenesp - Centro Nacional de Educação Especial, encarregado da definição da política da Educação Especial para o país. E é da década de 1980 a diretriz para a integração do "aluno excepcional" nas salas de aula "regulares", como direito às oportunidades iguais. $\mathrm{Na}$ mesma década, documentos mundiais que visam a inclusão social, como a Convenção de Direitos da Criança (1989) e a Declaração sobre Educação para Todos, são assinados.

Mas é na década de 1990, com a assinatura de documento elaborado na Conferência Mundial sobre Educação Especial, em Salamanca, na Espanha, que diretrizes básicas para a formulação e reforma de políticas e sistemas educacionais de acordo com o movimento de inclusão social tomam forma. A partir de então, com a chegada do século XXI, políticas e programas de inclusão que tornam as escolas públicas e privadas responsáveis também por esses processos têm se fortalecido no Brasil. Decretos publicados em sequência demonstram a atenção dada à educação, não mais tida como especial, mas sim como inclusiva:

Somado ao cenário apresentado, o Estado Brasileiro, como signatário da Organização das Nações Unidas (ONU) assumiu em 2008, através da Convenção sobre os direitos da pessoa com deficiência (p. 7), o compromisso de assegurar um sistema educacional inclusivo em todos os níveis.

Com isso, os eixos instituídos foram:

- constituição de um arcabouço político e legal fundamentado na concepção de educação inclusiva;

- institucionalização de uma política de financiamento para a oferta de recursos e serviços para a eliminação das barreiras no processo de escolarização; e - orientações específicas para o desenvolvimento das práticas pedagógicas inclusivas. 


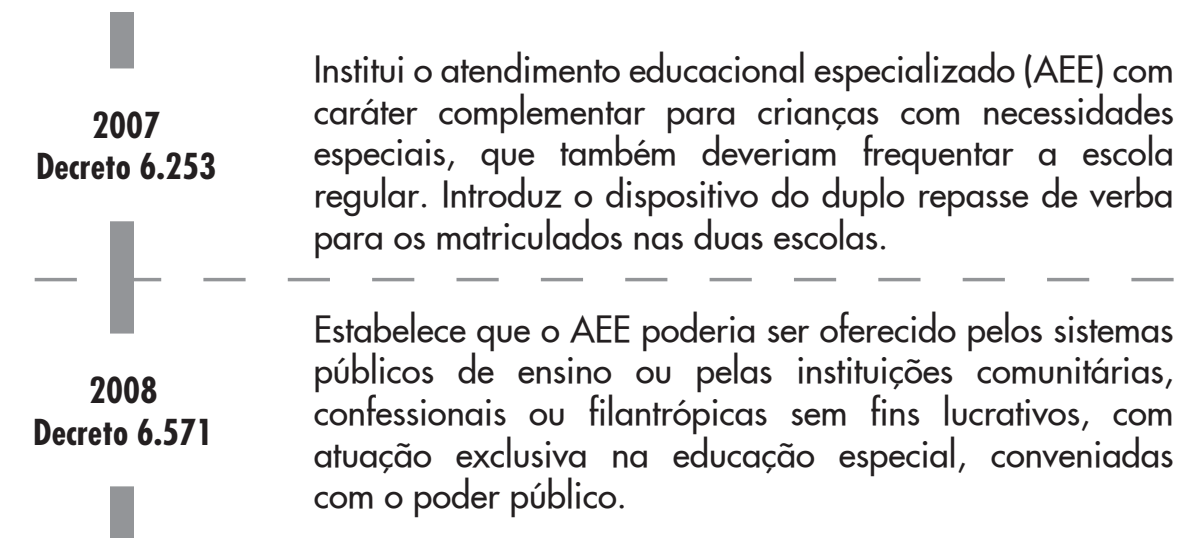

Meta número 4 prevê universalização do atendimento

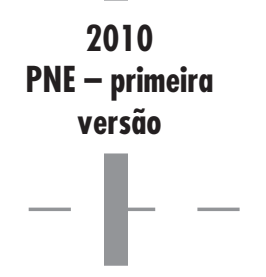
escolar para estudantes com deficiências, transtornos globais do desenvolvimento e altas habilidades ou superdotação na rede regular de ensino.

Afirma que o poder público estimulará o acesso ao $\overline{\mathrm{AEE}}$ de forma complementar ou suplementar ao ensino regular,

2011

Decreto 7.611

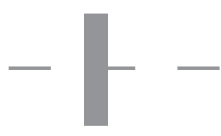
assegurando a dupla matrícula. Em contrapartida, estabelece que serão consideradas, para a educação especial, tanto as matrículas na rede regular de ensino como nas escolas especiais ou especializadas.

O novo texto da meta número quatro introduz o conceito de

2011

PNE - relatório

substitutivo que $\mathrm{o}$ atendimento escolar deve ser feito "preferencialmente" na rede regular de ensino, já que o atendimento educacional em escolas especializadas deve ser considerado sempre que "não for possível"a integração do aluno nas classes comuns.

2015

Lei n..$^{\circ}$ 13.146, de Lei Brasileira de inclusão da pessoa com deficiência.

\section{6 de julho de 2015}

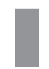

Figura 9.7: Revista Edraçãochline Principais decretos da educação inclusiva nos últimos anos

Percorrendo esse caminho, entre 2007 e 2013, por exemplo, segundo o Censo da Educação Básica realizado anualmente pelo Instituto Nacional de Estudos e Pesquisas Educacionais Anísio Teixeira (Inep), a porcentagem de estudantes com deficiência, transtornos globais do desenvolvimento e altas habilidades ou superdotação matriculados em salas de aula regulares cresceu de $46,8 \%$ para $76,9 \%$. 
Percentual de matrículas de alunos com deficiência, transtornos globais do desenvolvimento e altas habilidades ou superdotação na Educação Básica
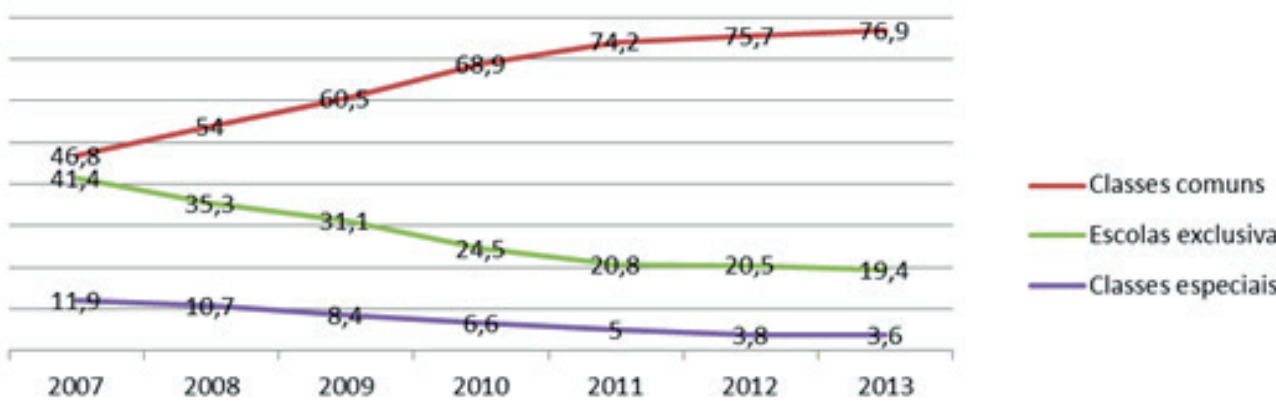

Escolas exclusivas

Classes especiais

Figura 9.8: Dados do INEP de percentual de matrícula de alunos com deficiência. Fonte: MEC/Ineep/DEED/Censo Escolar

\section{AC̣ÃO}

Agora feche seus olhos. Recupere suas lembranças como estudante. Nas salas de aula frequentadas por você havia crianças/jovens com deficiência, transtornos globais do desenvolvimento, altas habilidades ou superdotação? Mantenha-se de olhos fechados e pense no seu espaço escolar/acadêmico: havia classes especiais? No caso de respostas afirmativas, a escola/universidade estava preparada para acolher integralmente as crianças/jovens em questão? Registre suas impressões a partir de suas lembranças:

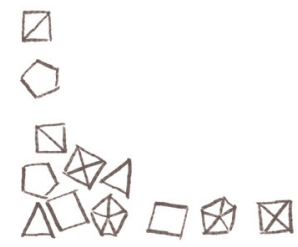

Figura 9.9: Espaço para reflexão. Fonte: LINC-Design 
Provavelmente, se você, assim como a autora deste artigo, frequentou escolas nas décadas de 1960-1970 ou mesmo na década de 1980, haverá muita chance de precisar deixar o espaço acima em branco. Salvo raríssimas exceções, a inscrição de todos num todo não correspondia à ideologia predominante.

É justamente esta constatação que mobiliza a escrita do presente artigo e que mobilizou a inserção do GT que o originou. Como mencionado anteriormente, fundamentalmente, tínhamos por objetivo trocar experiências no sentido de reunir olhares e ações sobre a educação inclusiva, para fomentar discussões interdisciplinares que ancorassem a formação/qualificação de um professor que, muitas das vezes, não vivenciou a experiência da Educação Inclusiva ao longo de toda sua formação, desde a educação infantil até o Ensino Superior.

Ainda durante a seleção dos resumos aprovados para o evento, foi possível observar a abrangência do tema inclusão na perspectiva dos autores (professores e pesquisadores). A associação dos resumos à temática educação inclusiva tomava por base critérios distintos como:

- influências ambientais - diferenças culturais (preconceitos e estereótipos/ instrução insuficiente ou inapropriada);

- transtornos de conduta - irritabilidade, explosões temperamentais e agressividade exagerada;

- transtornos emocionais - ansiedade, depressão, fobia, psicose;

- transtornos de aprendizagem - transtorno do déficit de atenção com hiperatividade (TDAH), dislexia, discalculia;

- transtornos globais - espectro autista, síndrome de Asperger, síndrome de Kanner, síndrome de Rett; e

- deficiência - física, visual, auditiva, mental.

Também foi possível identificar resumos que apresentavam relatos de experiências que propiciaram práticas de ensino "bem-sucedidas", entendidas como aquelas que despertaram e/ou mantiveram a motivação dos participantes. Esses, em linhas gerais, partiam do pressuposto de que na escola de hoje todos estão excluídos, havendo, então, metodologias, estratégias e práticas que propiciam momentos de inclusão.

Os trabalhos foram selecionados buscando tornar representativa a diversidade das propostas. Com isso, os trabalhos apresentados contemplaram os seguintes objetivos na relação com os critérios mencionados: 
Tabela 9.1: Propostas

\begin{tabular}{cc}
\hline Critérios & Objetivos \\
\hline influências & $\begin{array}{c}\text { analisar livros didáticos (LD) para EJA, demonstrando que a } \\
\text { ambientais }\end{array}$ \\
& $\begin{array}{c}\text { dissonância com os documentos oficiais da EJA, comprometendo assim } \\
\text { sua utilização em práticas pedagógicas adequadas a um processo de } \\
\text { aprendizagem significativo; }\end{array}$ \\
& propor roteiro orientador de professores na avaliação e seleção de \\
atividades e materiais didáticos para o ensino-aprendizagem na EJA, \\
participando da reinserção no sistema escolar brasileiro jovens e \\
adultos com trajetórias escolares truncadas.
\end{tabular}

\begin{tabular}{|c|c|}
\hline \multirow[t]{5}{*}{$\begin{array}{l}\text { transtornos } \\
\text { globais }\end{array}$} & $\begin{array}{l}\text { demonstrar carências na formação do professor nos eixos subjetividade, } \\
\text { linguagem e corpo, constatadas a partir da observação de práticas de } \\
\text { sala de aula, para propor a aproximação psicologia e educação, com } \\
\text { vistas ao atendimento educacional especializado e inclusivo; }\end{array}$ \\
\hline & $\begin{array}{l}\text { situar o Teatro como disciplina de sensibilização na formação do } \\
\text { professor e de potencialização da ação frente/junto a transtornos } \\
\text { globais a partir da análise de práticas teatrais desenvolvidas em } \\
\text { projetos de extensão; }\end{array}$ \\
\hline & $\begin{array}{c}\text { apontar, a partir da apresentação de vídeos demonstrativos, a manutenção } \\
\text { de barreiras emocionais, físicas e estruturais que atuam de encontro ao } \\
\text { conceito de educação inclusiva como um movimento para todos; }\end{array}$ \\
\hline & $\begin{array}{l}\text { descrever metodologia de design no desenvolvimento e observação de uso } \\
\text { do método de construção de bonecos com o reaproveitamento criativo de } \\
\text { resíduos sólidos para validar o boneco (e o teatro de bonecos) como forma } \\
\text { expressiva de construção de conhecimento para grupo com transtorno global; }\end{array}$ \\
\hline & $\begin{array}{l}\text { situar o design inclusivo como área específica de desenvolvimento de tecnologia } \\
\text { assistiva apta a desenvolver projetos em parceria com os agentes participantes } \\
\text { da educação inclusiva (alunos, professores, pais, gestores). }\end{array}$ \\
\hline deficiência & $\begin{array}{l}\text { demonstrar que livros didáticos desenvolvidos para o ensino da língua } \\
\text { portuguesa como segunda língua para a educação de surdos encontram-se em } \\
\text { dissonância com os processos de alfabetização e letramento, vistos como partes } \\
\text { indissociáveis no processo de leitura e escrita nos primeiros anos de ensino. } \\
\text { O uso de traduções em libras, em recursos multimodais, muitas das vezes tem } \\
\text { foco na alfabetização, vista como aquisição de tecnologia, e distancia-se do } \\
\text { letramento, visto como prática social referenciada nas condições de aquisição e } \\
\text { uso, do momento de aprendizagem do indivíduo; }\end{array}$ \\
\hline
\end{tabular}


Tabela 9.1: Propostas (contina)

\begin{tabular}{cc} 
Critérios & Objetivos \\
\hline apresentar recurso didático em libras que associa alfabetização \\
e letramento desenvolvido por professor como complemento a \\
livro didático para educação de surdos, com vistas a minimizar as \\
deficiências observadas nos livros didáticos disponíveis quando se \\
prioriza o letramento; \\
assistiva, desenvolvidos para transtornos e deficiências em disciplinas de \\
projeto do curso de Design da PUC-Rio, com vistas a inserir o design em \\
parceria como uma metodologia efetiva de desenvolvimento de materiais e \\
recurso com foco na inclusão.
\end{tabular}

Em linhas gerais, o GT constitui-se como um espaço de:

1) Reflexão sobre a dificuldade dos formadores quando materiais, recursos, tecnologias, estruturas e ambientes apresentam questões concretas que tornam inapropriado seu uso/ocupação por desconhecimento ou favorecimento da exclusão em detrimento a inclusão.

2) Proposição de uma formação profissional interdisciplinar, envolvendo, pelo menos, psicologia, teatro, design, estudos da linguagem e educação.

3) Reflexão sobre a necessidade de sensibilização para as diferenças, ressaltando que o professor de hoje foi formado em ambientes de exclusão.

4) Reflexão sobre a precariedade da inclusão atual (inscrição de todos num todo) como raiz de manutenção de discursos que valorizam a inscrição de todos em todos excludentes.

\section{CONSIDERAÇÕES DESENVOLVIDAS A PARTIR DO GRUPO DE TRABALHO}

Enfim diferente dos princípios da escola nova - nos quais, como já mencionado, (1) há a valorização da diversidade e o consequente favorecimento da inclusão; (2) há um entendimento de escola como vida, em detrimento de um sentido de preparação para a vida; (3) há o objetivo de propiciar a reconstrução constante da experiência e da aprendizagem no contexto da vida cotidiana - o que ainda se observa após a apresentação das comunicações no grupo de trabalho é a manutenção da estigmatização da figura dos indivíduos marcados como em situação de inclusão.

Foram claras, por exemplo, as diferenças entre professores oriundos de espaços de exclusão vinculados à inscrição de todos em todos excludentes, como os profes- 
sores do Instituto Nacional de Educação dos Surdos (INES), e professores oriundos de espaços inclusivos, no âmbito da inscrição de todos em partes de um mesmo todo, como os professores vinculados a escolas públicas e particulares do ensino regular da cidade do Rio de Janeiro. Enquanto os primeiros apresentavam familiarização com o "para quem" desenvolviam metodologias e práticas de ensino decorrentes da "vivência com", os segundos oscilavam entre um discurso otimista, decorrente de iniciativas individuais que resultavam em processos satisfatórios e prazerosos, e um discurso cético, oriundo da constatação de carências na formação para lidar com as diferenças e desfamiliarização com sujeitos, práticas, recursos e materiais.

Em ambos os casos, contudo, houve ênfase na valorização da democratização do ensino e da diversidade com respeito à individualidade, mas em muitos casos foi possível constatar que os docentes formadores foram formados "para a vida", em vez de "para vivenciarem a vida".

Em suma, a formação docente foi o ponto central para os diferentes posicionamentos. No âmbito da inscrição de todos em todos excludentes, o tempo de dedicação ao trabalho inclusivo das instituições de ensino, por exemplo, os quase dois séculos de existência do INES, propiciou uma preparação vivencial, no sentido vida-experiência dos formadores, amparada pela própria instituição de ensino da qual eles fazem parte, levando-os a assumirem um olhar otimista frente à inclusão, mas cético frente à inscrição de todos em partes de um mesmo todo na configuração em que ela vem se apresentando em cenário nacional. Já no âmbito da inscrição de todos em partes de um mesmo todo, foi visível a diferença entre os docentes oriundos das licenciaturas regulares, em especial Letras (por ser o foco dos seminários, livros e materiais de língua materna e estrangeira), e os docentes oriundos dos campos do design e das artes cênicas, pois enquanto os últimos expuseram suas formações vivenciais e experimentais, no sentido de terem desenvolvido em suas formações competências e habilidades vinculadas à representação e projetação, como fundamentos sólidos para o desenvolvimento de metodologias e práticas de ensino no contexto escolar com foco na inclusão, os primeiros ressaltaram que em sua formação docente e, sobretudo, em suas práticas de estágio supervisionado, pouco vivenciaram a inclusão.

Foi notória a preocupação com o "como fazer uso de" como ressaltado pela prevalência de comunicações que versaram sobre a inadequação de propostas inseridas em livros e materiais didáticos, quase que exclusivamente com proposições concretas de reformulação das atividades e manutenção das mídias, com excessão de uma comunicação que propunha a inserção da mídia boneco ${ }^{3}$ como recurso didático.

3 Tese de doutorado em andamento no Programa de Pós-Graduação em Design da PUC-Rio, no laboratório linguagem, interação e construção de sentidos, sob a orientação de Jackeline Lima Farbiarz. Previsão de defesa: 2017. 
A despeito dos simpósios terem em suas titulações as palavras livro, materiais e recursos, apenas em comunicações vinculadas à Educação de Jovens e Adultos - como, por exemplo, a que questionava ser o livro didático na EJA uma ferramenta para certificação ou para um processo de ensino-aprendizagem significativo - houve a clara alusão à pertinência de se trabalhar com livros didáticos que não contemplam o contexto situacional/perfil cultural do público-alvo. Assim, o "como fazer uso de" prevaleceu sobre os "o quê" e "por quê" utilizá-los.

Ficou claro, assim, que, apesar das diferentes e bem-sucedidas iniciativas apresentadas - como a que propunha uma releitura sobre as atividades propostas em livro didático para a educação de surdos, que resultou no desenvolvimento de um novo vídeo para uma das atividades do livro - ainda se trabalha na esfera cúbica para suprir necessidades em detrimento de se buscar abstração, criação e imaginação pressupostas pela harmonia cósmica decorrente do dodecaedro ${ }^{4}$. A situação nos leva a questionar o quanto em suas formações os docentes são preparados para não apenas refletir sobre livros, materiais e recursos didáticos, no sentido da funcionalidade e usabilidade, mas para propor soluções que entendam os objetos de uso e sistemas de informação como "objetos vivos", que, ao serem usados pelos sujeitos criam e comunicam suas identidades.

Os livros e materiais discutidos nas comunicações revelaram o desconhecimento frente ao público-alvo a que se destinam, e a inadequação das propostas contribuiu para a rotulação dos usuários de "incapacitados", no sentido de não terem adquirido habilidades necessárias para desenvolver as competências esperadas naquele momento de formação (Coleman, 1999). Situações como a presença de uma fotografia de um casal de aparência nórdica correndo pela areia em direção às águas cristalinas de uma praia como contextualização para uma atividade em que alunos de EJA deveriam aprimorar a capacidade de trazerem suas experiências cotidianas para a sala de aula, apresentando a si mesmos e suas ações, servem como ilustração ${ }^{5}$. Desconsidera-se, ainda hoje, que o prazer psíquico participa da formação e é pré-condição para o estabelecimento da empatia; sobretudo, desconsideram-se os níveis diferentes de experiência e de habilidade cognitiva dos envolvidos nas situações de ensino-aprendizagem e, consequentemente, atua-se em descompasso com uma visão holística das pessoas, dos produtos e das relações.

Foi possível constatar, também, a consciência das famílias acerca da falta de orientação para a constituição de uma escola inclusiva na esfera da inscrição de todos

4 Trabalho apresentado nos V SILID e IV SIMAR por Luciana Aparecida Guimarães de Freitas, intitulado "O livro didático na educação dos surdos: uma releitura sobre atividades propostas".

5 Trabalho apresentado nos V SILID e IV SIMAR por Janine Marta Pereira Antunes da Silva, intitulado "O livro didático na Educação de Jovens e Adultos (EJA): ferramenta para certificação ou para um processo de ensino/aprendizagem significativo?”. 
em partes de um mesmo todo. Tanto na mesa redonda que precedeu a reunião do grupo de trabalho quanto na atividade do grupo foi significativo o fato de o movimento de aproximação com o tema inclusão dever-se, na maioria das vezes, à presença de parente ou amigo com transtorno/deficiência. Filhos, netos e amigos desencadearam o foco na atividade docente e no desenvolvimento de pesquisas em educação inclusiva. Embora os motivos não tenham sido explicitados, ao longo das comunicações ficou claro que a opção pela pesquisa no tema partiu da necessidade de, por um lado, se instrumentalizar para lidar com a inclusão (que teve como resultado a frustração da percepção de que o cenário tem carências sérias) e, por outro, de familiarizar os sujeitos inscritos em contextos pedagógicos de inclusão. Neste sentido, foi significativa a comunicação práticas singulares de formação, na qual problematizou-se a relação de passividade frente a situações sociais, como o autismo por meio de práticas teatrais desenvolvidas junto aos docentes ${ }^{6}$.

Em linhas gerais, foi consenso que ainda prevalece o entendimento de que o indivíduo em situação de inclusão é visto como receptor dependente e passivo na maioria dos casos. Assim, a ele são ofertados livros, materiais, objetos, práticas e ambientes que buscam atender ao que pressupõem que lhes falta em detrimento de potencializar o que eles trazem e o que lhes é essencial. Busca-se a adequação a um modelo em consonância com o paradigma da incapacidade, impossibilitando-os de fortalecerem suas competências e habilidades.

\section{CONSIDERAÇÕES E PROPOSIC̣ÕES}

Sem dúvida, o GT demonstrou que muito se conquistou, mas também que muito se tem a conquistar. Causou impacto a frase apresentada pela diretora do Instituto Helena Antipof, proferida por um menino com deficiência intelectual na qual traça um questionamento acerca de seu lugar na escola, afirmando "se a escola não tem condições de acolhê-lo, deficiente é ela...”.

Sem dúvida, vive-se um momento de mudança de paradigma no qual é preciso pensar a formação do professor no contexto da interdisciplinaridade, habilitando-o para o conceito de que os processos de inclusão, educacionais ou não, dão-se no âmbito social.

Propondo o diálogo com a perspectiva de Bourdieu (1989) - a partir da qual o não domínio de códigos dominantes da comunicação em um determinado contexto inscreve o indivíduo em uma cultura "estrangeira" - constata-se, em linhas gerais, a partir dos trabalhos apresentados no GT, que no contexto educacional, a despeito dos avanços na legislação, há uma valorização da dificuldade do in-

6 Trabalho apresentado nos V SILID/IV SIMAR por Andréa Maria Favilla Lobo e Rafael Auler de Almeida Prado, intitulado "Práticas singulares de formação". 
divíduo a partir dos materiais e objetos de ensino-aprendizagem propostos. Há, por esse viés, o reforço das noções de capacidade/incapacidade e a consequente desvalorização das múltiplas inteligências que integram os indivíduos ao mundo.

Ainda na concepção de Bourdieu, o capital cultural estaria intimamente ligado ao sucesso escolar do indivíduo, partindo do princípio de que a escola e seus sistemas esperariam do aluno um tipo determinado de comportamento e um conhecimento linguístico que, por princípio, já no começo do processo educativo seria "excludente". Assim sendo, faz-se necessário reconsiderar o que a sociedade e a cultura escolar têm como referência de sucesso escolar, para que, deste modo, todos possam ser incluídos neste(s) critério(s).

A partir do momento em que os indivíduos em situação escolar não se sentem pertencente ao grupo dos "bem-sucedidos", eles tendem a não se integrar e/ou criar resistência e até mesmo abandonar a escola. Consideramos, desta forma, que as ações envolvidas no processo inclusivo educacional deveriam focar nas múltiplas inteligências $^{7}$ e não nas deficiências da criança. Acreditamos ser necessário um olhar interdisciplinar por parte dos atores envolvidos e atuações multidisciplinares.

É nesta perspectiva que ganha relevância o termo "arquitetônica", cunhado por Mikhail Bakhtin em escritos de 1919, 1920 e 1924.

a arquitetônica [...] entende que a diversidade que constitui o mundo resulta de um movimento interativo da própria diversidade. Em vez da arquitetura do edifício situado no espaço e pronto para ser usado, a arquitetônica exprime a qualidade das relações que não se oferecem diretamente ao olhar, mas se manifestam como projeção. Enquanto a mecânica mostra os posicionamentos, a arquitetônica persegue os fluxos e seus pontos de vista projetados sob forma de diferentes interações. [...] Nesse caso, a interação pressuposta no diálogo deve ser configurada na triangulação conceitual em que: arquitetura (construção) > mecânica (movimento) > arquitetônica (interação) $=$ resposta (sentido) (MAcHAdo; In: PAULA (Org.), 2010, s/p).

Pelo viés deste conceito, quer seja a concepção de práticas de ensino-aprendizagem, quer seja a concepção e eleição de objetos, recursos e tecnologias para ensino-aprendizagem, elas partem de agentes mediadores (gestores, professores) situados num espaço e tempo único e singular para os alunos inscritos em situação de inclusão, também situados num espaço e tempo únicos e singulares na existência. Assim, qualquer proposição terá lugar no encontro em um ponto específico, na tensão dinâmica da relação eu-outro, na interação em espaço-tempo determinado de singularidades, e é tanto consequência das subjetividades atuantes na interação quanto é produtor de subjetividades. Os usos resultantes das proposições dos agentes mediadores (detentores de um campo de visão determinado por um

7 Gardner, Howard. Frames of Mind: The Theory of Multiple Intelligences. New York: Basic,1983. 
posicionamento no espaço-tempo) e da resposta dos alunos (detentores de outro campo de visão, também determinado por um posicionamento no espaço-tempo) sobre a proposição em comum, assim como os aspectos em jogo no campo de visão de "eu" e de "outro", não são coincidentes, mas sim relacionais. As proposições situam-se no âmbito da construção de sentidos, mantendo-se inacabadas frente ao potencial de respostas que só se esgotam no findar da sociedade.

Sendo assim, participar da projetação de proposições para espaços potencialmente inclusivos, entre outros aspectos, significa reconhecer que o campo de visão do "agente mediador" se constitui tanto na projeção conceitual/imagem desse "aluno" para o qual se destina o projeto - projeção fundamentada em backgroud e horizonte de expectativas (ISER, 1996) - quanto no encontro e no diálogo em um ponto específico (espaço-tempo determinado), com esse "outro", durante o uso ou a ação do ou sobre a proposição projetada. Logo, a projetação sustenta-se no aceitar da diversidade, no reconhecer dos pré-conceitos e, fundamentalmente, numa mudança de concepção do projetar "para" o outro para o projetar "com" o "outro" como pré-condição para uma ação em constante ressignificação. Por este viés, o reconhecimento das noções de pertencimento, identificação e apropriação torna-se fundamental na dinâmica do processo da situação de projeto e nas distintas análises de uso, noções que participam da constituição dos campos de visão do "mediador" e do "aluno" com quem se projeta em uma dinâmica adaptável e cambiante de ressignificações (Bakhtin, 2003).

A reflexão acerca das discussões desencadeadas pelos trabalhos apresentados no GT demonstra que a formação do professor para a inclusão tem na arquitetônica o fio condutor para a interdisciplinaridade. Os trabalhos apresentados sob as óticas do teatro-design-educação-linguagem demonstraram isso. Em suma, foi a busca por "olhar, reconhecer e agir sobre os "fluxos que constituem um evento" que foram entendidas como potencializadoras das múltiplas inteligências que tornam os sujeitos singulares e constituem a diversidade.

Para a educação inclusiva, é preciso um novo desenho em um movimento para todos. Por este viés, a disciplina design, desenvolvedora de objetos, sistemas e serviços, entendida em sentido restrito como interface entre o produto que se cria e o usuário, apresenta-se como importante elemento na perspectiva interdisiciplinar por lidar com o vasto leque de preferências e capacidades individuais a partir de um olhar sobre as múltiplas inteligências. Nesse percurso, ela se insere como valor de projetação para questões plurais nas esferas histórica, política, econômica, social, antropológica, tecnológicas e ergonômica. É neste viés que ela encontra a coesão e a coerência com a inteligência do usuário e suas expectativas, agindo como desenvolvedora de objetos, sistemas e serviços facilitadores de nossa participação em um mundo construído que nos insere em "caixas". Sem o novo desenho para a educação, sustentado por um de- 
sign participativo inclusivo, os espaços de ensino-aprendizagem, seus recursos e tecnologias correm o risco de se manterem privilegiando a estigmatização, via valorização da "limitação" em detrimento ao pertencimento.

Em suma, é oriundo deste cenário que o professor se encontra em sala de aula hoje na condição de docente. Rever sua formação é viabilizar o atendimento às novas diretrizes, pois a imposição de leis em dissonância com um projeto de formação do docente e dos gestores gera resultados extremamente prejudiciais, como os discutidos no GT.

$\mathrm{Na}$ realidade brasileira, gestores e professores, em linhas gerais, não são formados para o diálogo com as novas demandas. Na realidade brasileira, espaços, materiais e recursos não são construídos e desenvolvidos em consonância com as novas demandas, salvo raras exceções.

O GT demonstrou que, de fato, é urgente seguir a recomendação da Organização Mundial de Saúde (OMS) de fortalecer e apoiar a pesquisas com objetivo de aumentar a "compreensão pública sobre questões relacionadas à deficiência", "a oferta de informações para a elaboração de programas e políticas dedicados à deficiência", e "a alocação eficiente de recursos para a construção de massa crítica de pesquisadores na área”.

Recuperando os pressupostos da Escola Nova, a função da escola deve ser a de propiciar uma reconstrução permanente da experiência e da aprendizagem dentro da vida do aluno. Sem isso, não há democracia ou os direitos de oportunidades iguais perante a lei. O GT demonstrou um conjunto de boas intenções, mas uma carência de ação, realização e concretização política, que, conforme entendemos, deverá percorrer um caminho cada vez mais multidisciplinar.

\section{REFERÊNCIAS}

BOURDIEU, P. O poder simbólico. São Paulo: Editora Bertrand, 1989.

BAKHTIN, M. Estética da Criação Verbal. São Paulo: Martins Fontes, 2003.

CONVENÇÃO SOBRE OS DIREITOS DAS CRIANÇAS. 1989. Disponível em: $<$ https://www.unicef.pt/docs/pdf_publicacoes/convencao_direitos_crianca2004. pdf $>$. Acessado em: 10 maio 2016.

FARBIARZ, J. L. \& RIPPER, J. L. M. Instantâneos de interações. Rio de Janeiro: PUC-Rio, 2010.

FAZENDA, I. C. A. (Org.). Integração e interdisciplinaridade no ensino brasileiro: efetividade ou ideologia? São Paulo: Loyola, 1979.

FULLER, R. B. Manual de operação para a Espaçonave Terra. Brasília: Ed. Universidade de Brasília, 1979. 
GOULEMOT, J. M. Da leitura como produção de sentidos. In CHARTIER, R. [org.] Práticas de Leitura. Tradução de Cristiane Nascimento. São Paulo: Estação Liberdade, 1996. p. 107-116.

HALL, M.J.D., ROBERTS, P.H. e TAYLOR, A.J. Understanding Person Product Relationship - A design Perspective, Human Factors in Product Design - Current practice and Future trends. London: Taylor \& Francis, 1999. p. 218-228.

HOLQUIST, M. Dialogism. Bakhtin and his World. Londres: Routledge. 1990.

HOLQUIST, M. e LIAPUNOV, V. Art and Answerability. Early Philosophical Essays by M. M. Bakhtin. Austin: University of Texas Press. 1990.

ISER, W. O Ato da Leitura - Uma Teoria do Efeito Estético. (vol. 1 e 2). São Paulo: Editora 34, 1996. [1ª. Edição 1976]

JAPIASSU, H. Interdisciplinaridade e Patologia do Saber. Rio de Janeiro: Editora Imago, 1977.

JORDAN, P.W. Inclusive design - Design for All. In: Human Factors in Product Design - Current practice and Future trends. London: Taylor \& Francis, 1999. p. 171-181

JORDAN, P.W. Pleasure with Products, Human Factors for Body, Mind and Soul. In: Human Factors in Product Design - Current practice and Future trends. London: Taylor \& Francis, 1999. p. 206-217.

MACHADO, I. “A questão espaço-temporal em Bakhtin: cronotopia e exotopia”. In: PAULA, L. de; Stafuzza, G. (Orgs). Círculo de Bakhtin: teoria inclassificável. Série Bakhtin - Inclassificável. Vol. 1. Campinas: Mercado de Letras, 2010, p. $89-116$

MANIFESTO DOS PIONEIROS DA EDUCAÇÃO NOVA. 1932. Disponível em: $<$ http://cpdoc.fgv.br/producao/dossies/JK/artigos/Educacao/ManifestoPioneiros>. Acessado em: 15/05/2016.

PRESIDÊNCIA DA REPÚBLICA CASA CIVIL (Subchefia para Assuntos Jurídicos). Convenção sobre os direitos da pessoa com deficiência. Decreto $\mathrm{N}^{\circ} 6.949$, de 25 de agosto de 2009.

GOVERNO DE SÃO PAULO. Relatório sobre deficiência. 2012. Disponível em: $<$ http://www.pessoacomdeficiencia.sp.gov.br/ultimas-noticias/relatorio-mundial-sobre-a-deficiencia-apresenta-nove-recomendacoes>. Acesso em: 15 maio 2016. 
